\title{
Gestão da Qualidade e Princípio da Eficiência: uma Análise da Prestação de Serviços nas Universidades Públicas da Cidade de Petrolina-PE
}

\author{
João Leonardo da Silva Melo ${ }^{1}$; Norileide Oliveira da Silva ${ }^{2}$; Andressa Pacífico Franco Quevedo ${ }^{3}$
}

Resumo: A elevada qualidade no atendimento é constantemente buscada no âmbito do setor privado, todavia, no setor público ainda não é dos fatores mais relevantes, a despeito da reforma gerencial de 1995, a qual introduziu a obrigação de a administração pública obedecer ao princípio da eficiência, sendo implícito neste último o dever de desburocratização, busca da eficácia com qualidade a todos os funcionários públicos. O presente trabalho teve o intuito de avaliar a qualidade na prestação dos serviços públicos sob a perspectiva dos alunos de instituições de ensino superior públicas da cidade de Petrolina - PE. A pesquisa foi realizada através de questionário e avaliou aspectos ligados diretamente aos recursos humanos e à instituição em si, de uma maneira geral os resultados foram positivos, mas o ideal é que a administração pública busque cada vez mais a excelência, não devendo se contentar com resultados tão somente satisfatórios.

Palavras chave: Qualidade. Reformagerencial. Princípio da eficiência. Pesquisa. Excelência.

\section{Quality Management and Efficiency Principle: An Analysis of Provision of Services in the Public UnivComment}

\begin{abstract}
The high quality of service is constantly pursued in the private sector, however, the public sector is not the most relevant factors, despite the management reform of 1995 which introduced the obligation of the government to obey the principle of efficiency, and implicit in the latter the duty of reduce bureaucracy, search for efficiency with quality to all civil servants. This study aimed to evaluate the quality in the provision of public services from the perspective of students in public higher education institutions in the city of Petrolina - PE. The survey was conducted through a questionnaire and evaluated aspects connected directly to human resources and the institution itself, in general the results were positive, but the ideal is that the government seek increasingly excellence and should not be content with so only satisfactory results.
\end{abstract}

Keywords: Quality. management reform. Principle of efficiency. Search. Excellence.

Introdução

A qualidade no atendimento é um aspecto fundamental, levado muito asério pelos mais diversos tipos de organizações privadas, o investimento nesse quesito é alto, e a educação, a cordialidade, a maneira com a qual são tratados os clientes pelos trabalhadores pode ser determinante para uma demissão ou para a contratação de um novo funcionário que venha agradar mais a clientela de determinadas empresas.

\footnotetext{
${ }^{1}$ Graduado em Direito pela Faculdade de Ciências Aplicadas e Sociais de Petrolina - FACAPE. E-mail: jlmelo10@ hotmail.com;

${ }^{2}$ Graduação em pela Faculdade de Ciências Aplicadas e Sociais de Petrolina - FACAPE / Universidade de Pernambuco - FFPP/UPE. E-mail: nileidesilva@yahoo.com.br;

${ }^{3}$ Mestre em Administração pela Universidade Federal de Pernambuco (UFPE). Professora Assistente da Universidade Federal Rural de

Pernambuco. Especialista em Gestão da Capacidade Humana nas Organizações pela Universidade de Pernambuco (UPE). Graduada em

Turismo pela Universidade Federal de Pernambuco (UFPE). E-mail: andressadm@ gmail.com.
} 
O setor privado depende de lucros e não pode se dar ao luxo de perder clientes por conta da má prestação de seus serviços. Corroborando tal afirmação, "empresas de sucesso são as que satisfazem totalmente seus clientes" (KOTLER; KELLER, 2006, p. 138). Bom, a administração de empresas já se deu conta do quanto é necessário investir nesse fator. Mas, e a administração pública, leva a sério tal quesito?

Pode-se dizer que deveria levar, já que um dos princípios basilares da administração pública é o da eficiência, inclusive expressamente previsto no artigo 37 da Constituição Federal e dele obviamente derivam a necessidade de eficácia, presteza, celeridade com qualidade. Segundo alguns autores (MORAES, 2002 apud NOHARA, 2006), dentre as características da eficiência estão o "direcionamento à efetividade do bem comum, imparcialidade, neutralidade, transparência e aproximação dos serviços públicos da população, eficácia, desburocratização e busca da qualidade".

Em busca da desburocratização, o Estado vem promovendo mudanças ao longo do tempo, sabido, inclusive, que vem sendo perseguida desde a década de 90 uma transição do modelo burocrático de administração pública para o modelo gerencial, conhecida mais especificamente por reforma administrativa gerencial de 1995 e foi especificamente desta reforma que segundo Nohara (2006), decorreu a Emenda Constitucional de 1998, a qual acrescentou expressamente à Constituição da República Federativa do Brasil, o princípio da eficiência entre os demais princípios que a administração pública deve se pautar, ou seja, perseguir em todas as suas ações.Contudo, mesmo com a já citada reforma, a burocracia ainda continua forte na administração do estado, ainda de acordo com Silva e Guimarães (2014), a gestão pública brasileira passou por três modelos diferentes: a administração patrimonialista, burocrática e a administração gerencial. Essas modalidades surgiram sucessivamente ao longo do tempo, não significando,entretanto, que alguma delas tenha sido definitivamente abandonada.

A burocracia tem o condão de controlar abusos, todavia, seu excesso de formalismo a torna indesejável para os anseios do cidadão, para quem deve servir a máquina pública. Sobre o tema, colocam-se da seguinte maneira, Silva e Guimarães (2014, p.25): "Superar as práticas de gerenciamento da gestão burocrática e tradicional é um dos principais desafios da gestão pública gerencial e participativa".

Os níveis de qualidade no atendimento e de eficiência na prestação do serviço público são decorrentes de diversos fatores, todos eles ligados de certa forma ao servidor público, à maquina humana, aos chamados recursos humanos. É possível notar inclusive diferenças no atendimento e na qualidade do serviço prestado de um setor para o outro, dentro de um mesmo órgão, dessa maneira o já citado princípio da eficiência passa inevitavelmente pela pelo agir do funcionário público.

Paladine, (2012, p. 179) nos informa que "o recurso básico de geração da qualidade é o funcionário público". 
O estudo do comportamento organizacional é muito importante para ajudar a determinar o quanto fatores comportamentais influenciam diretamente na prestação do serviço público, mas, há fatores extras, fatores diversos que podem ser examinados e que devem ser levados em consideração quando da análise da forma de agir do funcionário para com o recebedor do serviço público, dentre esses fatores extra comportamentais estão a estrutura de trabalho oferecida pelo estado, as condições de trabalho que são dadas ao servidor, a carga de trabalho a que está submetido determinado servidor, dentre outros.

Verificar o quanto tais fatores influenciam no desenvolvimento das atividades do funcionário público é dessa maneira fundamental para entender como a administração pública pode aos poucos buscar soluções para aumentar a eficiência dos serviços prestados de uma maneira geral. Para investigar tais quesitos, nada melhor do que o cliente do estado, o cidadão, aquele que precisa dos serviços prestados pela máquina pública.

Na cidade de Petrolina existem atualmente três Instituições de Ensino Superior públicas, duas delas mais antigas e atuantes há mais tempo e uma última bem mais nova, são elas, a Faculdade de Ciências Aplicadas e Sociais de Petrolina - FACAPE, a Universidade de Pernambuco - UPE e a Universidade Federal do Vale do São Francisco - UNIVASF respectivamente. Todas públicas, entretanto a primeira municipal, a segunda estadual e a terceira federal, todas com o mesmo serviço oferecido aos cidadãos, a oferta e manutenção de cursos superiores de graduação e ainda de pósgraduação.

O papel social das universidades para com a comunidade é fundamental, importante e sem dúvida deve ser mantido, pesquisar e estudar sobre os problemas sociais e ainda sobre possíveis soluções para tais problemas deve continuar sendo o forte das instituições de ensino superior. Mas por que não estudar sobre as próprias Universidades? Por que não saber se as Universidades funcionam de acordo com o que espera o usuário dos seus serviços?

O intuito da presente pesquisa é realizar um levantamento acerca da qualidade em relação aos serviços prestados por estas três importantes instituições de ensino, que recebem alunos de Petrolina PE e de diversas cidades circunvizinhas.Após tal levantamento, analisar os respectivos dados, verificando as diferenças nos resultados, ou mesmo as semelhanças, no intuito de entender num momento posterior o que é feito internamente, ou que muda entre uma instituição e outra que pode ser determinantena boa gestão da qualidade.

\section{A importância da qualidade na prestação dos serviços}

Obviamente o a discussão central do presente trabalho gira em torno prestação de serviços no setor público, sobre este enfoque cabe destacar a importância que tem a gestão da qualidade em 
serviços no âmbito das empresas privadas, ou seja, realizar uma comparação. A princípio, utilizamos da definição de serviço trazida por Paladine (2012, p. 160). Para o autor "serviço é sempre uma ação desenvolvida por terceiros, em atendimento à solicitação explícita, específica e bem definida de um usuário determinado". Ainda segundo o autor (...), em geral, esses terceiros habilitam-se a realizar o serviço por possuírem qualificação própria para tanto".

Voltando à importância da qualidade no atendimento para o setor privado, especificamente em se tratando de atendimento, de acordo com Paladine (2012, p. 167), é a Gestão de Qualidade,

"notadamente direcionada para ações em busca de maior contato com o cliente, definição de seus interesses, preferências, exigências, necessidades, conveniências, enfim, tudo o que ele possa considerar relevante no processo de prestação do serviço".

O autor ainda conclui ressaltando que "em um primeiro momento, portanto, a Gestão da Qualidade prioriza a eficácia; a seguir a eficiência e a produtividade. O conceito elementar da qualidade nesse ambiente, assim, é o de perfeita adaptação do processo ao cliente". O modelo de gestão da qualidade no atendimento é o que irá diferenciar determinada empresa no mercado de trabalho, e permitirá ainda nas palavras de Paladine (...) diferenciar a empresa no mercado, possibilitando a obtenção da fidelidade do usuário. Verifica-se assim que a qualidade na prestação do serviço é que vai determinar a sobrevivência das empresas privadas, nesse diapasão pode-se citar o chamado Benchmarking, que tem o intuito de verificar por meio de processo contínuo o quão competitivos são os processos frente aos dos concorrentes, através da comparação com outras empresas, integrantes do mesmo ambiente em que ela está incluída, percebe-se que a busca pela excelência é exercida de maneira contínua no setor privado.

Ao tratar ta questão da qualidade na prestação de serviços, Kotler e Keller (2006, p. 145), aduzem que a "qualidade é a totalidade dos atributos e características de um produto ou serviço que afetam sua capacidade de satisfazer necessidades declaradas ou implícitas (...) Podemos dizer que a empresa fornece qualidade sempre que seu produto ou serviço atende às expectativas do cliente ou as excede".

Já no setor público, tal como anteriormente citado, ainda que com reformas, mesmo com a entrada em vigor da chamada administração pública gerencial, aliada à gestão por resultados, o estado ainda deve em qualidade no atendimento, de acordo com Paladine (2012, p. 175), "Uma pesquisa feita por uma rede de emissoras de televisão de Florianópolis em novembro de 2011 mostrou que cerca de 80\% dos catarinenses consideram o serviço público (nos três níveis estaduais, municipais e federal) de péssima qualidade”. E como já trazido no início do presente texto, a qualidade no atendimento passa indubitavelmente pelo funcionário público, é nele que devem ser concentrados os esforços de melhoria no processo de gestão da qualidade do estado. Vejamos: “(...) O funcionário repassa para a sociedade 
Id on Line Revista Multidisciplinar e de Psicologia

Id on Line Multidisciplinary and Psychology Journal

os benefícios (como também restrições) de sua satisfação no trabalho. A qualidade de seu atendimento, assim, é diretamente proporcional à qualidade de suas relações com o empregador, no caso, o Estado" (PALADINE, 2012, p.179).

Acredita-se assim que uma pesquisa de tal cunho possa dar uma melhor perspectiva aos leitores do presente estudo sobre as diferenças encontradas nas gestões do ensino superior nas três esferas de governo, municipal, estadual e federal, todas em uma mesma cidade, inseridas num mesmo contexto.

\section{Pesquisa}

Inevitável no presente estudo deixar de fazer comparações entre o ramo empresarial e a administração pública, nesse sentido interessante ressaltar o que vem fazendo algumas empresas a fim de verificar o sentimento de seus clientes em relação aos seus produtos e serviços, surge nesse cenário o que foi denominado por Kotler e Keller (2006, p. 143). de "Medida de satisfação", os autores destacam que "muitas empresas estão medindo sistematicamente a satisfação do cliente e os aspectos que a influenciam. A IBM, por exemplo, monitora a satisfação do cliente a cada visita de seus vendedores e, na hora de calcular a remuneração desses vendedores, utiliza essa medida como fator". Por que não medir a satisfação dos "clientes" do estado então? Ou seja, os usuários do serviço público.

\section{A opinião do corpo discente}

Para ajudar a investigar a qualidade na prestação dos serviços públicos universitários os personagens do presente estudo não podiam ser outros se não os alunos, uma vez que uma universidade não existe sem os discentes, e é a princípio para eles que é constituído tal órgão público, o papel das universidades é formar profissionais, através prestação de serviços educacionais, e os usuários destes serviços são os alunos, os quais convivem diariamente com os servidores públicos, não há dúvidas que os discentes têm uma visão, um ponto de vista privilegiado em relação aos serviços desempenhados pela administração das suas respectivas instituições de ensino. Ademais, antes de assumirem a qualidade de alunos, os participantes da pesquisa são cidadãos que de uma forma genérica estão se utilizando um serviço público. Dessa maneira, no intuito de investigar o que fora inicialmente proposto neste estudo, lançou-se uso de técnica bastante utilizada em trabalhos acadêmicos. 


\section{Material e métodos}

No intuito de aferir a opinião dos alunos de cada uma das instituições de ensino superior públicas da cidade de Petrolina - PE (FACAPE, UPE e UNIVASF) foi elaborado um questionário contendo dez (10) questões objetivas (fechadas), a exemplo de: 1. Em relação à prestação de um serviço do qual tenha precisado, ao avaliar as ações do funcionário que lhe atendeu, considerando o que você acha que estava ao alcance do mesmo naquele momento, ou seja, o que ele podia fazer para resolver o problema. Ao receber a demanda e lhe dar uma resposta, pode-se dizer que o funcionário foi: (Ineficiente/ Razoavelmente eficiente/ Eficiente/ Muito eficiente/ Não se aplica); 2. Ainda que não sejam responsáveis por resolver determinada demanda, os funcionários sabem direcionar o aluno para a resolução da questão? (Sim/ Não/ Não sei/ Não se aplica); 3. Em relação à cordialidade dos funcionários para com os alunos, na sua opinião, os funcionários: (Não são cordiais, São razoavelmente cordiais, São cordiais, São muito cordiais, Não sei); 4. Em se tratando da avaliação apenas dos funcionários, como classifica a prestação de serviços pelos mesmos? (Péssima/ Ruim/ Satisfatória/ Boa/ Ótima); 5. Na sua opinião, a quantidade de funcionários da sua instituição de ensino para a demanda de trabalho atual é: (Insuficiente/ Adequada/ Mais que suficiente/ Não sei); 6. Em relação ao item anterior, você acha que a sobrecarga de trabalho influencia na qualidade dos serviços prestados por tais funcionários? (Sim/ Não/ É indiferente/ Não sei); 7. Em relação à organização da sua universidade, você encontra facilmente o setor procurado quando necessita de algum serviço? (Sim/ Não/ Não sei/ Não se aplica) 8. Quão Profissional considera a sua instituição? (Nada profissional/ Razoavelmente profissional/ Profissional/ Muito profissional/ Não sei/ Não se aplica); 9. Em geral, você está satisfeito com o serviço prestado pela sua instituição? (Muito insatisfeito/ Insatisfeito/ Satisfeito/ Muito satisfeito/ Extremamente satisfeito);

10. Em sua opinião, que ações poderiam ser adotadas para se alcançar cada vez mais uma elevada qualidade na prestação dos serviços? (Oferecer treinamento constante aos funcionários/ Contratar mais funcionários/ Melhorar a remuneração (salário dos funcionários) / Investir mais em fatores motivacionais/ Outros). O referido instrumento foi aplicado aleatoriamente a 20 (vinte) alunos de cada uma das instituições, por amostra de conveniência. Ou seja, vinte (20) alunos na instituição municipal, vinte (20) alunos na instituição estadual e vinte (20) alunos na universidade federal. Perfazendo um total de sessenta (60) participantes na pesquisa.

A pesquisa contém (10) dez quesitos, divididos basicamente em três blocos com intuitos diferentes.

O primeiro bloco de questões, composto pelas questões de números 01 (um) a 04 (quatro) buscou avaliar a opinião dos alunos em relação aos funcionários, foram verificados através das perguntas aspectos como o nível de eficiência dos servidores de cada instituição, a capacidade de ajudar na resolução da demanda, ainda que não seja responsável o servidor buscado pelo aluno, além 
disso, os alunos foram questionados sobre a cordialidade dos funcionários públicos durante o serviço, terminando a avaliação dos funcionários, os discentes universitários foram convidados a avaliar de uma forma global a prestação dos serviços em cada uma de suas instituições.

O segundo bloco do questionário contém as perguntas 05 (cinco) e 06 (seis) e objetivou analisar sob a perspectiva dos usuários do serviço universitário como anda um ponto específico das condições de trabalho dos servidores, a quantidade de funcionários para a demanda do órgão.

O terceiro e último bloco de perguntas, compreendido entre o sétimo $\left(7^{\circ}\right)$ e o décimo $\left(10^{\circ}\right)$ quesitos, foi voltado não para a avaliação dos funcionários, mas para a avaliação da universidade em si, o órgão, foram investigados fatores como a organização e o profissionalismo da instituição na opinião dos entrevistados, além disso, verificou-se o nível de satisfação global dos alunos quanto aos serviços que a eles é prestado, por fim os alunos opinaram a respeito de possíveis ações que poderiam ser adotadas na busca constante pela melhora do serviço público universitário.

$\mathrm{O}$ instrumento de pesquisa usou essencialmente perguntas objetivas, e a ferramenta contou ainda com um termo de consentimento, o qual deixava claro que o entrevistado não precisaria se identificar, visando principalmente manter a privacidade do mesmo.

\section{Resultados e discussão}

Para a discussão dos resultados, deve-se considerar que os vinte (20) alunos participantes na faculdade municipal (FACAPE) equivalem a 100\% dos respondentes deste estabelecimento, assim como os vinte (20) alunos da universidade estadual (UPE) equivalem a 100\% dos participantes desta instituição e por fim, que os vinte (20) voluntários da instituição de ensino federal (UNIVASF) equivalem a $100 \%$ dos participantes entrevistados nesta respectiva universidade. A porcentagem traz uma melhor percepção dos dados obtidos, além disso, o uso demasiado de números pode comprometer a compreensão dos resultados. Todavia, em alguns momentos o valor expresso em números absolutos se mostrará mais eficaz para a exposição, motivo pelo qual a informação será expressa dessa maneira.

No primeiro quesito, todos os participantes foram perguntados, de forma resumida sobre qual seria o nível de eficiência de um determinado funcionário quando demandado pelos respectivos alunos, levando em consideração o tempo entre o que foi demandado e a resposta dada ao discente, como alternativas foram propostas as seguintes sentenças: ineficiente, razoavelmente eficiente, eficiente, muito eficiente e por fim "não se aplica" para o caso de discentes que jamais tenham necessitado dos serviços institucionais. Sobre tal avaliação, a princípio cabe informar que nas três instituições não houve respostas com a alternativa "não se aplica", assim, supõe-se que todos os participantes, em determinado momento de sua vida acadêmica necessitaram de algum serviço institucional. Em seguida, o dado que mais chamou a atenção é que tanto na universidade estadual, 
quanto na federal, nenhum dos alunos classificou o serviço prestado por um funcionário como "muito eficiente", houve, entretanto na faculdade municipal um (1) dos participantes que avaliou o serviço prestado como "muito eficiente", o que equivale a $5 \%$ dos votos. No quesito / "eficiente" apenas a instituição federal teve mais da metade dos votos, foram exatamente $55 \%$ dos votos, restando empatadas nesse mesmo quesito as instituições estadual e municipal com 35\% dos votos, dessa maneira ficaram empatadas também estas duas últimas no quesito "razoavelmente eficientes", ambas com 55\% dos participantes opinando, nesse mesmo quesito a universidade federal ficou com $30 \%$ dos votos de seus alunos. Por fim, classificaram como ineficiente o serviço 15, 10 e 5\%, dos alunos das faculdades federal, estadual e municipal respectivamente. Avaliando de uma maneira geral este primeiro quesito, pode-se observar que as instituições obtiveram valores parecidos, crê-se, entretanto, que a universidade federal restou mais equilibrada já que somente nela mais da metade dos alunos disse ter um serviço eficiente, chama atenção ainda na avaliação das respostas, o empate das instituições estadual e municipal no quesito "razoavelmente eficiente" com 35\%, mas de uma maneira geral não foram verificados valores discrepantes.

No segundo quesito os entrevistados foram questionados da seguinte maneira "Ainda que não sejam responsáveis por resolver determinada demanda, os funcionários sabem direcionar o aluno para a resolução da questão?”. Aqui surpreendentemente também é possível notar certo equilíbrio, já que disseram que sim 65, 60 e 55\% os alunos da estadual, da municipal, e da federal respectivamente, na mesma ordem disseram que o funcionário não sabia direcionar o aluno 30, 20 e 30\% dos alunos, o restante dos participantes disse "não se aplica" para a resposta, ficando os valores quase idênticos para todas as universidades. Verifica-se assim que no presente quesito a universidade estadual ficou melhor colocada, enquanto a municipal no meio termo e a federal a menos indicada, ainda que mais da metade dos alunos ache que os funcionários sabem sim direcionar os discentes. Tais resultados talvez tenham decorrido de uma maior ou menor quantidade de setores dentro de cada faculdade, o que pode facilitar a indicação de outro setor responsável ou ainda ao maior conhecimento dos respectivos servidores quanto ao funcionamento dos demais setores de seus atinentes órgãos, há ainda a possibilidade de um só setor concentrar mais atribuições. Quanto à observação dos resultados, mais uma vez restam equilibrados.

$\mathrm{Na}$ terceira questão, foi avaliada a opinião dos discentes quanto à cordialidade dos funcionários. E na opinião de 55\% dos alunos, os funcionários da instituição federal são cordiais, enquanto $35 \%$ dos alunos consideram os funcionários da autarquia municipal cordiais, e somente $20 \%$ dos alunos da estadual acham cordiais os respectivos funcionários. No sentido oposto, avaliando o item "são razoavelmente cordiais" marcaram tal assertiva 55\% dos alunos das instituições estadual e municipal, enquanto apenas $20 \%$ dos alunos da federal assim responderam. Por fim responderam que não são cordiais os funcionários, $10 \%$ na municipal, $15 \%$ na federal e $25 \%$ na estadual. Aqui, é possível notar claramente que a instituição de ensino estadual é a pior avaliada em qualquer das 
assertivas. Necessário se faz um estudo mais aprofundado sobre fatores comportamentais, ambiente de trabalho e demais causadores do resultado aqui encontrado.

Quanto ao quarto quesito, e ultimo relacionado estritamente à avaliação dos funcionários, foram convidados os participantes da pesquisa a avaliar de uma maneira global a qualidade dos serviços prestados pelo funcionário. Aqui houve uma surpresa em relação aos itens anteriormente avaliados, já que em se tratando do nível de eficiência e de cordialidade os resultados na maioria das vezes mantiveram-se próximos dos 50\%, os resultados da presente avaliaçãogiraram entre $65 \%$ e $70 \%$ de respostas ao item "satisfatória" para os órgãos municipal, estadual e federal, estes dois últimos empatados com o maior valor, ficando restante dos votos, certa de $30 \%$ bem divididos entre "ruim" e "boa", este último, um nível acima de satisfatória na escala da questão e aquele um nível abaixo. Dessa maneira, avaliando o quesito relacionado àsatisfação global dos serviços prestados pelos funcionários, é possível dizer que os resultados foram bem melhores aqui do que nos itens anteriores.

A partir da quinta questão, tal como afirmado no início do presente estudo, a avaliação deixa de recair propriamente sobre os funcionários e busca verificar a opinião dos alunos quanto a um item especifico, que de certa forma poderia influir nos resultados das avaliações anteriores, a quantidade de funcionários, o presente item foi assim apresentado: "Em sua opinião, a quantidade de funcionários da sua instituição de ensino para a demanda de trabalho atual é:” até aqui, em relação às respostas, os valores foram os mais discrepantes, e o dado que mais chama atenção é o da universidade estadual, $75 \%$ dos alunos avaliaram que a quantidade de funcionários da instituição é insuficiente, na autarquia municipal o valor é de 50\%, apenas na universidade federal os alunos o valor ficou abaixo da metade dos entrevistados com $20 \%$ crendo ser insuficiente a quantidade de funcionários de sua instituição. Em contrapartida o restante dos participantes (25\%) da UPE disseram ser adequada a quantidade de funcionários, na instituição municipal esse valor foi de $40 \%$ e na federal de $60 \%$. Daí conclui-se que na percepção dos alunos faltam servidores na instituição estadual, e na municipal, enquanto acham estar adequada a quantidade de funcionários, os alunos na UNIVASF.

No sexto item outros resultados consideráveis foram apurados, perguntados se quanto ao item anterior, ou seja, a quantidade de funcionários, a "sobrecarga de trabalho influenciaria na qualidade dos serviços prestados por tais funcionários?" $80 \%$ dos alunos na instituição estadual disseram que sim, a sobrecarga de trabalho influencia na qualidade dos serviços prestados, tal opinião inclusive teve mais da metade dos votos nas outras academias $75 \%$ dos alunos da federal também acreditam ser a sobrecarga de trabalho fator determinante na qualidade dos serviços prestados, na municipal 55\% dos alunos. Na estadual e na federal o restante dos poucos votos restou dividido basicamente entre "não", "é indiferente" e "não sei". Apenas na faculdade municipal esses itens obtiveram valores um pouco mais expressivos em que $25 \%$ disseram não saber e os outros $20 \%$ dividiram-se entre "é indiferente" e "não sei". 
A partir do sétimo quesito, o intuito foi a avaliação da instituição em si, começando com a seguinte pergunta: "Em relação à organização da sua universidade, você encontra facilmente o setor procurado quando necessita de algum serviço?" Aqui a universidade federal obteve considerável vantagem, $80 \%$ dos discentes disse que sim, encontram facilmente o que procuram, contudo, os valores para as outras instituições não foram por demais insatisfatórios já que mais da metade dos entrevistados também disse encontrar facilmente o que procura nas universidades estadual e municipal, especificamente 55\% em ambas. Importante frisar que nenhuma das instituições teve um valor tão elevado de respostas "não" como teve a UPE, já que embora esteja a mesma empatada com a FACAPE na avaliação positiva, esta última teve o restante dos votos divididos entre "não" $25 \%$ e "não sei” $20 \%$. Assim, chama atenção a quantidade de alunos que disse não encontrar facilmente o setor procurado na universidade estadual, necessário se faz uma investigação futura sobre a organização das três universidades, a fim de verificar o que há de diferente na estrutura interna dos três órgãos.

$\mathrm{Na}$ oitava questão os entrevistados foram convidados a avaliar de uma maneira global o quanto acham profissionais suas respectivas instituições. Os resultados aqui se mostraram mais favoráveis que preocupantes, $60 \%, 65 \%$ e $60 \%$ dos alunos da instituição municipal, estadual e federal respectivamente consideram suas instituições "profissionais" na mesma ordem 40\%, 30\%, e 30\% disseram que sua respectiva instituição é "razoavelmente profissional". Por fim, os $10 \%$ da estadual disseram que sua instituição é "nada profissional", enquanto os $10 \%$ da federal afirmaram ser "muito profissional" a sua instituição. Pode-se dizer que foi uma avaliação positiva já que em todos os casos $60 \%$ ou mais disseram que as instituições são sim profissionais, contudo, importante ressaltar que havia ainda a assertiva: "muito profissionais", podendo-se afirmar que a maioria dos alunos ficou em um meio termo, entre "nada profissional" e "muito profissional".

A nona questão questionava se o aluno, de uma maneira geral estava satisfeito com o serviço prestado pela sua respectiva universidade, e aqui o resultado da questão anterior se confirmou, mais uma vez todas as instituições tiveram acima dos $60 \%$ de fotos para "satisfeito", especificamente as seguintes porcentagens $75 \%, 65 \%$ e $80 \%$ para a municipal, a estadual e a federal respectivamente, ficando o restante dos votos para a assertiva "insatisfeito" 25\% para a municipal, 20\% para a federal, $25 \%$ da estadual, está ultima ainda obteve 1 volto para "muito satisfeito" e um voto para "muito insatisfeito" correspondendo ambos a 5\% em porcentagem. As observações aqui ficam mais uma vez para o fato de que a grande maioria dos alunos ficou no meio termo, ou seja, a avaliação não foi péssima, nem ótima, mas mediana, ou satisfatória.

A décima e última questão, já não mais avaliou, apenas solicitou de uma forma objetiva a sugestão dos alunos sobre o que poderia ser feito em busca de uma evolução constante, a pergunta foi a seguinte: "Em sua opinião, que ações poderiam ser adotadas para se alcançar cada vez mais uma elevada qualidade na prestação dos serviços?". Neste ultimo quesito as alternativas eram as seguintes: "Oferecer treinamento constante aosfuncionários", "Contratar mais funcionários", "Melhorar a 
remuneração/saláriosdos funcionários", "Investir mais em fatoresmotivacionais" e "Outros". Embora as respostas tenham sido bem divididas em todos os casos, para todas as instituições, a resposta que prevaleceu foi "Oferecer treinamento constante aos funcionários" com 45\%, 40\% e 45\% dos alunos participantes da municipal, da estadual e da federal respectivamente, o segundo item mais votado para a FACAPE foi "outros" (20\%), "contratar mais funcionários" para a UPE com $35 \%$ dos votos, e "investir mais em fatores motivacionais" para os alunos da UNIVASF com (20\%). O restante dos votos ficou decomposto entre os demais itens. Sendo importante observar que todos os demais itens receberam votos, o que mostra que para o usuário do serviço a solução, ou a simples melhora da prestação dos serviços pode passar por diversos fatores.

\section{Conclusão}

No decorrer do presente estudo foi possível verificar a enorme importância que tem a gestão da qualidade para as empresas privadas, o quanto tal ramo investe e considera fundamental a satisfação dos clientes, além disso, o texto trouxe aspectos da conhecida administração pública burocrática, bem como da chamada administração pública gerencial, ressaltando a reforma pela qual passou o Brasil na década de 90, a qual tinha o objetivo de trazer exatamente uma transição do país do modelo burocrático de administração para o citado modelo gerencial, verificou-se que é inerente a este último modelo a adoção do princípio da eficiência como norte, tal princípio por sua vez tem como suporte basilar elementos indubitavelmenteassociados à celeridade, à eficácia e à qualidade, dentre outros. Foi demonstrado que quanto à qualidade, esta é frequentemente medida no setor privado, através da satisfação dos clientes.

Nesse esteio o presente trabalho propôs uma pesquisa, a fim de medir a satisfação dos "clientes", dessa vez dos clientes do estado, ou seja, os cidadãos que se utilizam do serviço público, mais especificamente a investigação abordou alunos de universidades públicas no intuito de verificar o quanto os mesmos estão satisfeitos com os serviços prestados pelas suas respectivas instituições de ensino. Referida pesquisa se mostrou instrumento eficiente na aferição do que se propunha, e trouxe, a considerar a visão que se tem de administração pública, resultados de certa forma imprevistos, já que de uma maneira geral é possível afirmar que a maioria dos resultados relacionados à qualidade e a eficiência mantiveram-se em um patamar mediano de satisfação dos usuários do serviço, ou seja, a avaliação de uma maneira global teve resultados voltados para o padrão dito (satisfatório) de qualidade, é claro que os resultados não foram unânimes, houve sim usuários (insatisfeitos) com os serviços dos quais eles usufruem, bem como houve casos de alunos (mais que satisfeitos) com a prestação dos serviços, mas esse foi o padrão das três universidades públicas comparadas, cabe destacar, cada uma das instituições é relacionada a uma diferente esfera de governo, municipal, 
estadual e federal. Houve é claro, casos isolados de respostas que chamaram a atenção, como no caso da percepção dos alunos sobre a quantidade de funcionários de suas instituições, em que a maioria dos alunos no caso das instituições municipal e estadual disseram ser insuficiente o efetivo de servidores para a demanda atual, e em ambos os casos concordaram que esse fator pode afetar a qualidade da prestação dos serviços públicos, valendo frisar que tais resultados foram ainda mais acentuados no caso da instituição de ensino estadual, o que por si só já é motivo para despertar o olhar mais atento dos respectivos gestores para tal fator. Chamou ainda atenção o fato de que quando questionados sobre alternativas para melhoria contínua dos serviços públicos, os alunos das três instituições em sua maioria acreditarem que o oferecimento constante de cursos de capacitação para os funcionários pode trazer cada vez mais, melhores resultados.

Por fim, cabe dizer que seria pretensioso por demais acreditar que a administração pública atingisse níveis elevadíssimos de satisfação e qualidade na avaliação dos usuários de seus serviços, mas é importante destacar que os resultados foram além do esperado, entretanto, aquém do que deveriam estar, óbvio como visto que a administração pública está em constante mudança e evolução, e é natural que o processo não seja dos mais rápidos, mas o ideal é que a administração passe a buscar e venha a atingir níveis de excelência, tal como os constantemente perseguidos pelo setor privado.

\section{Referências}

BRASIL. Constituição da República Federativa do Brasil. Disponível em: http://www.planalto.gov.br/ccivil_03/constituicao/ConstituicaoCompilado.htm. Acesso em $12 / 03 / 2016$.

Brasil. Emenda Constitucional n. 19, de 4 de junho de 1998. Disponível em: http://www.bresserpereira.org.br/ver_file_3.asp?id=1499. Acesso em 22/04/2016.

KOTLER, Philip; KELLER, Kevin Lane. Administração de marketing. 12. ed. São Paulo: Pearson Prentice Hall, 2006. Tradução: Monica Rosenberg, Brasil Ramos Fernandes, Claudia Freire. Revisão Técnica: Dilson Gabriel dos Santos.

NOHARA, Irene Patrícia. Direito Administrativo. 3. ed. São Paulo: Atlas, 2006.

PALADINE, Edson Pacheco. Gestão da Qualidade: Teoria e Prática. 3. ed. São Paulo: Atlas, 2012.

REFORMA GERENCIAL DE 1995. Disponível em: http://www.bresserpereira.org.br/rgp.asp. Acesso em 20/04/2016.

SILVA, Vânia Liberato e GUIMARÃES, Maria da G. Vitório. A evolução da administração pública brasileira: Do patrimonialismo à gestão participativa. Estudos de casos em administração pública. Manaus: EDUA, 2014. 
Id on Line Revista Multidisciplinar e de Psicologia

Id on Line Multidisciplinary and Psychology Journal

Como citar este artigo (Formato ABNT):

MELO, J.L.S.; SILVA, N.O.; QUEVEDO, A.P.F. Gestão da Qualidade e Princípio da Eficiência: Uma análise da Prestação de Serviços nas Universidades Públicas da Cidade de Petrolina - PE. Id on Line Revista Multidisciplinar e de Psicologia, Julho de 2016, vol.,10 n.30, Supl 1. p. 131-143. ISSN 1981-1179.

Recebido: 10/05/2016

Aceito: 14/05/2016 